\title{
Investigation of the Weldability of Austanitic Stainless Steel
}

\author{
E. M. Anawa, M. F. Bograrah, S. B. Salem \\ Industrial and Manufacturing Department, Faculty of Engineering, University of Benghazi, Benghazi, Libya \\ Email: ezzeddin.anawa @uob.edu.ly
}

Received 4 April 2014; revised 8 May 2014; accepted 2 June 2014

Copyright (C) 2014 by authors and Scientific Research Publishing Inc.

This work is licensed under the Creative Commons Attribution International License (CC BY). http://creativecommons.org/licenses/by/4.0/

(c) (i)

\begin{abstract}
This work concerns with the study of weldability of austenitic stainless steel 316 by using automatic tungsten gas shielded arc welding under various welding conditions under which it is designed to weld the samples. Results have been studied using impact and tensile strength tastings of the prepared welding joints using statistical approach. Results obtained showed that as gas flow rate of $\left(\mathrm{CO}_{2}\right)$ increased the impact energy is increased, while increasing of welding current caused increasing of impact energy up to (120 ampere) then decreased. The tensile strength test results showed that as welding current is increased the tensile fracture load is decreased while increasing gas flow rate caused an increase in tensile fracture load up to $12 \mathrm{~L} / \mathrm{min}$ then reduced. Microstructure examination of the weld zones did support the explanation of the variation of weld joint mechanical properties.
\end{abstract}

\section{Keywords}

\section{Weldability, Austenitic Stainless, Impact Energy, Tensile Strength}

\section{Introduction}

The austenitic stainless steels, because of their high chromium and nickel content, are the most corrosion resistant of the stainless group providing unusually fine mechanical properties. Austenitic is the most widely used type of stainless steel. It has a nickel content of at least of 7\%, which makes the steel structure fully austenitic and gives it ductility, a large scale of service temperature, non-magnetic properties and good weld ability. The range of applications of austenitic stainless steel includes house wares, containers, industrial piping and vessels, architectural facades and constructional structures [1]. Murat et al. [2] have studied on the resistance spot weldability of galvanized interstitial free steel sheets with austenitic stainless steel sheets. In microhardness measurements, the maximum hardness values were in the middle of the weld nugget. Emin Bayraktar et al. [3] have 
contributed their research on the selection of optimal welding conditions and developed new grade steels for automotive applications. The study is based on impact tensile testing to spot welded sheets. The effect of nucleus size on mechanical properties in electrical resistance spot welding of chromide micro alloyed steel sheets was investigated by Aslanlar [4]. Effects of Laser Welding Conditions on Toughness of Dissimilar (austenitic stainless steel 316 with low carbon steel F/A) Welded Components were investigated by E. M. Anawa and A.G. Olabi [5] using Taguchi approach to optimize the dissimilar F/A joints in terms of its mechanical properties.

Bouyousfi et al. [6] have studied the effect of process parameters (arc intensity, welding duration and applied load) on the mechanical characteristics of the weld joint of austenitic stainless steel 304L. The results showed that the applied load seems to be the control factor of the mechanical characteristics of weld joint compared to the welding duration and the current intensity. Nizamettin K [7] has focused his study on the influence of welding parameters on the joint strength of resistance spot-welded titanium sheets. The results indicated that increasing current time and electrode force increased the tensile shear strength and the joint obtained under the argon atmosphere gave better strength. Hardness measurement results showed that welding nugget gave the highest hardness. L. Suresh Kumar et al. [1] experimentally investigated welding aspects of AISI 304 and 316 by taguchi technique for the process of TIG \& MIG welding. They used the TIG and MIG process to find out the characteristics of the metal after it is welded. The voltage is taken constant and various characteristics such as strength, hardness, ductility, grain structure, modulus of elasticity, tensile strength breaking point, HAZ are observed in two processes and analyzed and finally concluded. V. Shankar et al. [8] investigated the solidification cracking which is a significant problem during the welding of austenitic stainless steels, particularly in fully austenitic and stabilized compositions. They studied the solidification cracking in austenitic stainless steels with particular emphasis on nitrogen-alloyed and stabilized stainless steels. A statistical design of experiment (DOE) was used to optimise selected laser beam welding parameters (laser power, welding speed, and focus length). Optimization of tensile strength of ferritic/austenitic laser welded components was studied by E.M. Anawa and A.G. Olabi [9]. The experimental results indicate that the F/A laser welded joints are improved effectively by optimizing the input parameters using the Taguchi approach. The aim was to optimize the maximum ultimate tensile strength of F/A welded components, by minimizing the laser power and maximizing welding speed in order to optimize the cost and increase the production rate.

This work concerns with the study of weldability of austenitic stainless steel 316 by using automatic tungsten gas shielded arc welding under various welding conditions under which it is designed to welded the samples. The mechanical properties such as tensile strength and notch impact strength are tested and investigated.

\section{Experimental Work}

\subsection{Base Metal Selection}

The base metal used in the present work was stainless steel type (Austenitic 316) the dimensions are: $(1250 \times$ $1000 \times 2 \mathrm{~mm}(1 \times \mathrm{w} \times \mathrm{h}))$, the chemical compositions and the mechanical properties are shown in Table 1 and Table 2 respectively.

Table 1. Chemical composition of base metal.

\begin{tabular}{cccccccccc}
\hline Element & $\mathrm{Cr}$ & $\mathrm{Ni}$ & $\mathrm{Mn}$ & $\mathrm{Si}$ & $\mathrm{C}$ & $\mathrm{N}$ & $\mathrm{Nb}$ & $\mathrm{Ti}$ & $\mathrm{Fe}$ \\
\hline Weight $\%$ & $16-18$ & $10-14$ & $1-2$ & 0.08 & $0.02-0.08$ & $0-0.015$ & $<0.2$ & $<0.2$ & balance \\
\hline
\end{tabular}

Table 2. Mechanical properties of base metal.

\begin{tabular}{cc}
\hline \multicolumn{1}{c}{ Mechanical Properties } \\
\hline Density $(\times 1000 \mathrm{Kg} / \mathrm{m})$ & 7.8 \\
Poisson's Ratio & $0.27-0.30$ \\
Elastic Modulus (GPa) & 200 \\
Tensile Strength (MPa) & 515 \\
Yield Strength (MPa) & 205 \\
Elongation (\%) & 40 \\
Reduction in Area (\%) & 50 \\
\hline
\end{tabular}




\subsection{Welding Process}

The welding process was carried out by using TIG technique for welding process, this technique is widely used for different kinds of welding processes. The welding machine type is (PHOENIX 500) this machine can be used for multi welding processes such as: (TIG, MIG) technique, TIG welding technique was selected for this study to produce the joint for selected welding parameters. The welding process was carried out without filler metal.

\subsection{Samples Preparation}

The selected material was cut by using an electrical shear to (20) samples, which are exhibited in Figure 1. Than the welding process was applied to join samples at different welding conditions which are presented in Table 3 , using butt joint design, exhibited in Figure 2.

\subsection{Weld Joints Testing}

\subsubsection{Non Destructive Testing (Visual Inspection)}

In an attempt to find any flout in the welded joints such as (cracks, pores, etc.) and the welding penetration. The applied visual inspection was shows that acceptable quality of joints.

\subsubsection{Destructive Testing}

\section{- Tensile Test}

Tensile tests were carried out at room temperature $\left(25^{\circ} \mathrm{C}\right)$, for all the prepared tensile samples. The machine test and the diagram for tensile samples are shown in Figure 3 and Figure 4.

\section{Tensile Samples Preparations}

After finished the welding process the samples intended to be used for the tensile test were prepared, they were cut by using a hacksaw and no high temperature was generated that keeps the metal properties away from phase transformations, then the shaping machine was used to obtain a V groove at the welded area, to prepare a Notched Tensile Strength (NTS) as shown in Figure 4 [10]. For each welding condition five samples were prepared for tensile test.

\section{- Impact Test}

This test was carried out in (Mechanical Engineering Department) at room temperature $\left(25^{\circ} \mathrm{C}\right.$ ), for all the impact samples. The impact testing machine diagram and the impact samples are shown in Figure 5 and Figure 6. For each welding condition five samples were prepared for impact test.

Table 3. Experimental welding conditions.

\begin{tabular}{ccccccccccccc}
\hline \multicolumn{2}{c}{ Sample No. } & 1 & 2 & 3 & 4 & 5 & 6 & 7 & 8 & 9 & 10 \\
\hline \multirow{2}{*}{$\begin{array}{l}\text { Welding } \\
\text { Conditions }\end{array}$} & GFR, (L/min) & 10 & 10 & 10 & 10 & 10 & 7 & 8 & 10 & 12 & 14 \\
& $\mathbf{C},(\mathbf{A})$ & 80 & 100 & 120 & 160 & 180 & 120 & 120 & 120 & 120 & 120 \\
\hline
\end{tabular}

*GFR: Gas Flow Rate, C: Current

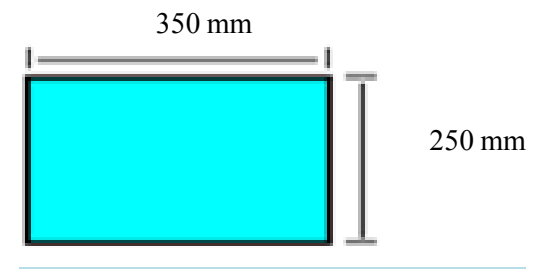

Figure 1. Material after cutting process.

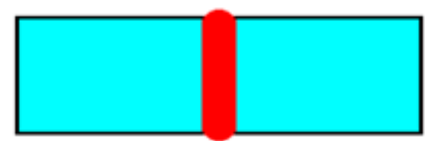

Figure 2. The welded sample. 


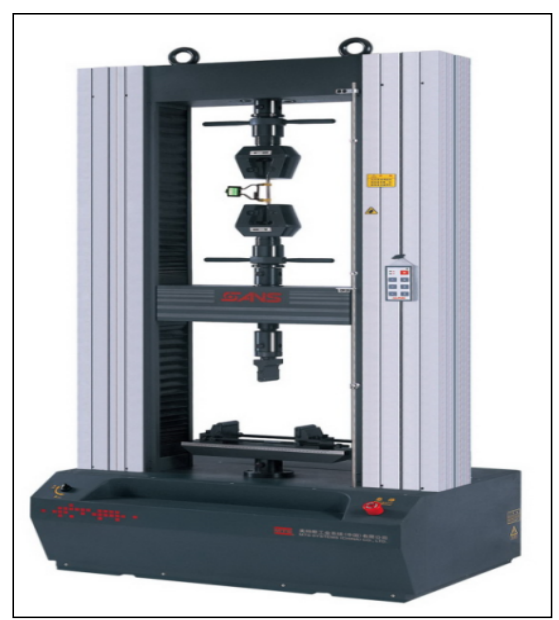

Figure 3. Tensile testing machine.
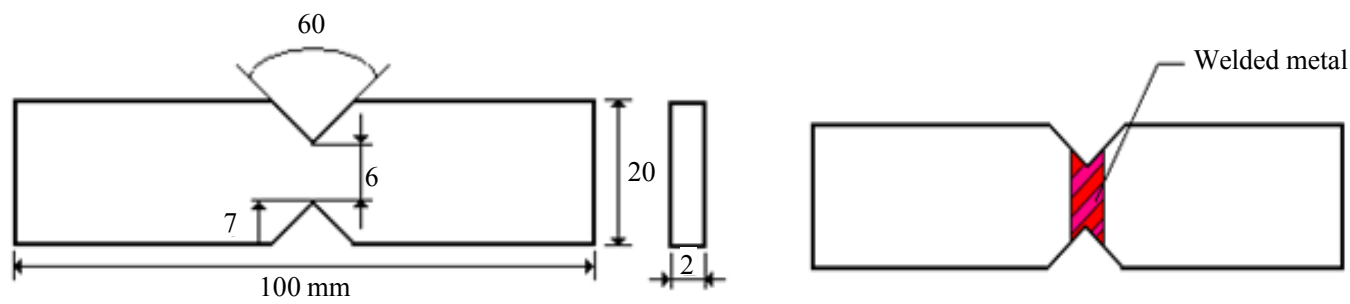

Figure 4. Schematic diagram for notched tensile strength (NTS).

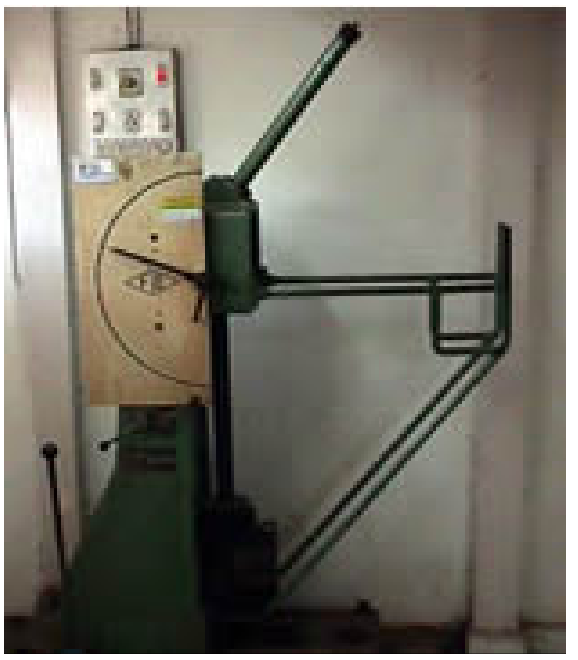

Figure 5. Impact testing machine.

Vgroove

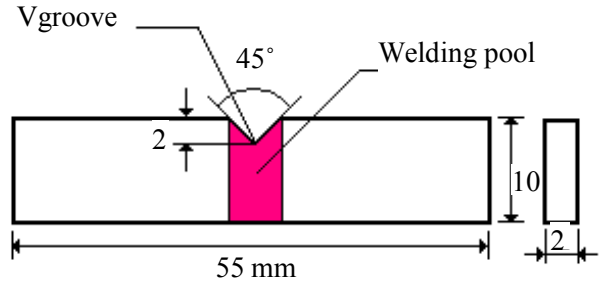

Figure 6. Schematic diagram of impact testing sample. 


\section{Impact Samples the Preparation}

After finishing the welding process the samples for the impact test were prepared, they were cut by using a hacksaw and no heat was introduced to keep the metal properties away from phase transformations, then the shaping machine was used to obtain a V groove in the welded area Figure 6.

\subsubsection{Microstructure Testing}

Microstructure study was carried out in Mechanical Engineering Department. A small sample was cut from each welded plate to study the microstructure. Emery papers grades $(80,500$, and 800$)$ were used for grinding the samples before polishing. For etching stainless steel, a $(1 \mathrm{~g})$ meta sulphate by meta sodium and $(20 \mathrm{ml})$ of HCL and $(100 \mathrm{ml})$ of distilled water was applied as an etchant. Microscopic examination was carried out using the ZIESS type optical microscope in Mechanical Department at Material laboratory at Benghazi University.

\section{Results and Analysis}

Following welding process and preparing of samples, the testing process was performed and the results obtained are exhibited in Tables 4-7 and represents in Figures 7-10.

The result analyses for the effect of gas flow and welding current on the mechanical properties are as follows:

Table 4. Results of impact test.

\begin{tabular}{ccccccc}
\hline \multirow{2}{*}{ Current (A) } & \multicolumn{7}{c}{ Gas Flow (10 L/min) } \\
\cline { 2 - 7 } & $\mathbf{1}$ & $\mathbf{2}$ & $\mathbf{3}$ & $\mathbf{4}$ & $\mathbf{5}$ & Average \\
\hline $\mathbf{8 0}$ & 22 & 17 & 16 & 14 & 26 & 19 \\
$\mathbf{1 0 0}$ & 29 & 30 & 26 & 24 & 24 & 26.6 \\
$\mathbf{1 2 0}$ & 30 & 30 & 22 & 24 & 28 & 26.8 \\
$\mathbf{1 6 0}$ & 32 & 30 & 24 & 20 & 26 & 26.4 \\
$\mathbf{1 8 0}$ & 24 & 30 & 22 & 26 & 24 & 25.2 \\
\hline
\end{tabular}

Table 5. Impact testing result.

\begin{tabular}{ccccccc}
\hline $\begin{array}{c}\text { Gas Flow } \\
(\text { L/min) }\end{array}$ & $\mathbf{5}$ & \multicolumn{2}{c}{ Current (120 A) } \\
\hline $\mathbf{7}$ & 26 & $\mathbf{2}$ & $\mathbf{3}$ & $\mathbf{4}$ & $\mathbf{5}$ & Average \\
$\mathbf{8}$ & 24 & 24 & 20 & 26 & 24 \\
$\mathbf{1 0}$ & 30 & 26 & 30 & 24 & 26 & 25.6 \\
$\mathbf{1 2}$ & 24 & 30 & 24 & 24 & 24 & 25.6 \\
$\mathbf{1 4}$ & 30 & 32 & 30 & 20 & 24 & 25.6 \\
\hline
\end{tabular}

Table 6. Readings of tensile test.

\begin{tabular}{ccccccc}
\hline \multirow{2}{*}{ Current (A) } & \multicolumn{5}{c}{ Gas Flow $(\times \mathbf{1 0}$ L/min) } \\
\cline { 2 - 7 } & $\mathbf{1}$ & $\mathbf{2}$ & $\mathbf{3}$ & $\mathbf{4}$ & $\mathbf{5}$ & Average \\
\hline $\mathbf{8 0}$ & 900 & 800 & 900 & 900 & 850 & 870 \\
$\mathbf{1 0 0}$ & 900 & 1000 & 900 & 900 & 900 & 920 \\
$\mathbf{1 2 0}$ & 900 & 920 & 800 & 820 & 850 & 858 \\
$\mathbf{1 6 0}$ & 950 & 800 & 850 & 900 & 820 & 864 \\
$\mathbf{1 8 0}$ & 800 & 800 & 900 & 800 & 800 & 820 \\
\hline
\end{tabular}


Table 7. Readings of tensile test.

\begin{tabular}{|c|c|c|c|c|c|c|}
\hline \multirow{2}{*}{$\begin{array}{l}\text { Gas Flow } \\
\text { (L/min) }\end{array}$} & \multicolumn{6}{|c|}{ Current (120 A) } \\
\hline & 1 & 2 & 3 & 4 & 5 & Average \\
\hline 7 & 900 & 1000 & 900 & 940 & 970 & 942 \\
\hline 8 & 830 & 980 & 900 & 850 & 820 & 876 \\
\hline 10 & 860 & 900 & 950 & 900 & 970 & 916 \\
\hline 12 & 950 & 1000 & 950 & 900 & 940 & 948 \\
\hline 14 & 940 & 910 & 900 & 960 & 920 & 926 \\
\hline
\end{tabular}

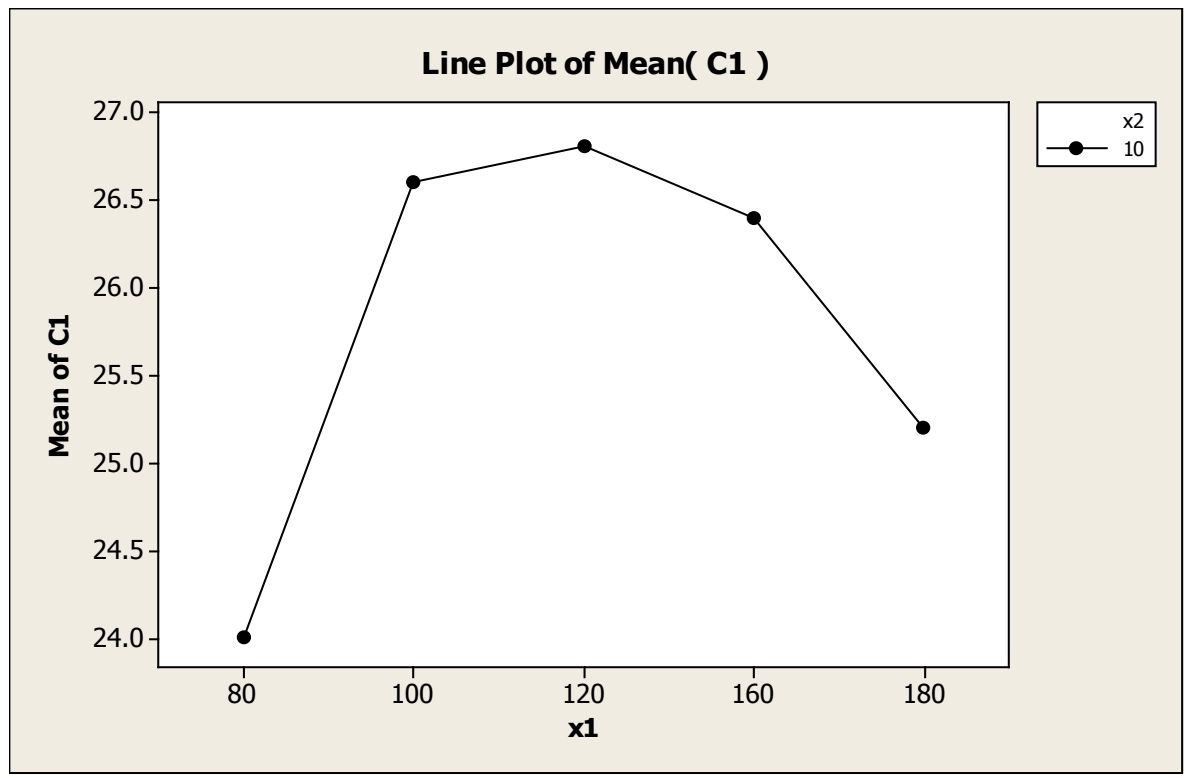

Where: The $\mathbf{X}$ axis is presenting the gas flows. The $\mathbf{Y}$ axis is presenting the mean of readings of impact tests.

Figure 7. Plot of impact test.

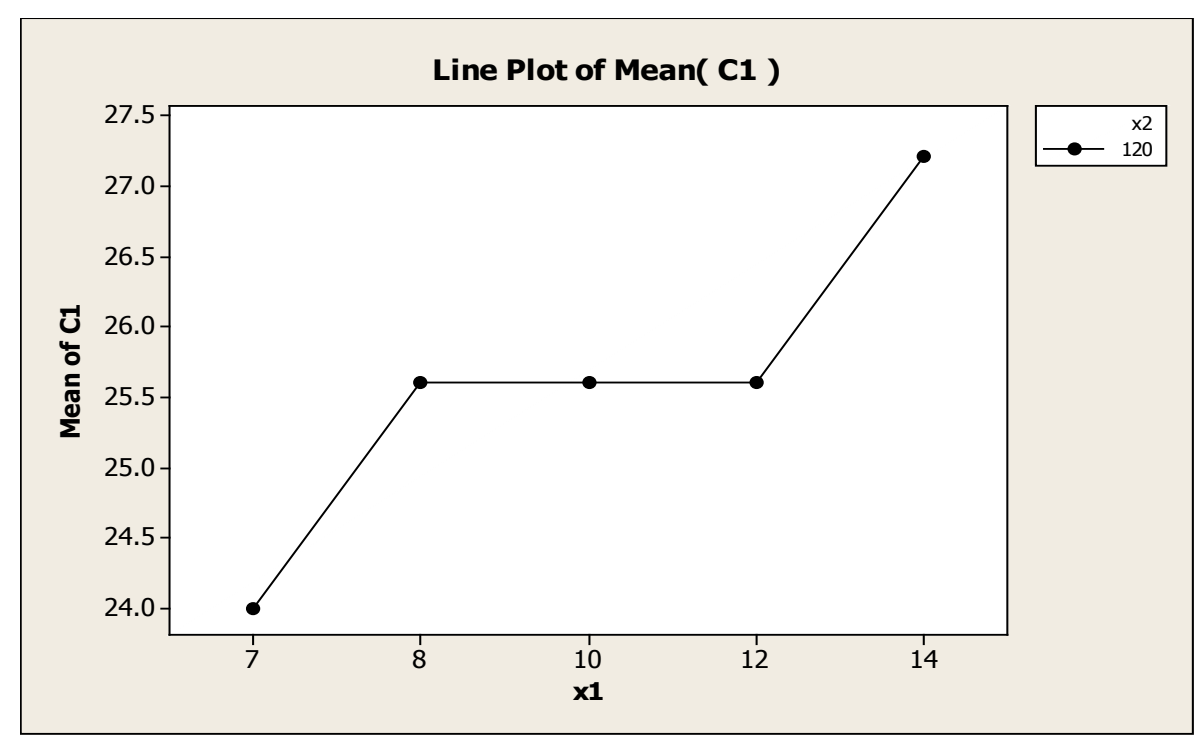

Where: The $\mathbf{X}$ axis is presenting the gas flows. The $\mathbf{Y}$ axis is presenting the mean of readings of impact tests.

Figure 8. A plot of impact test. 


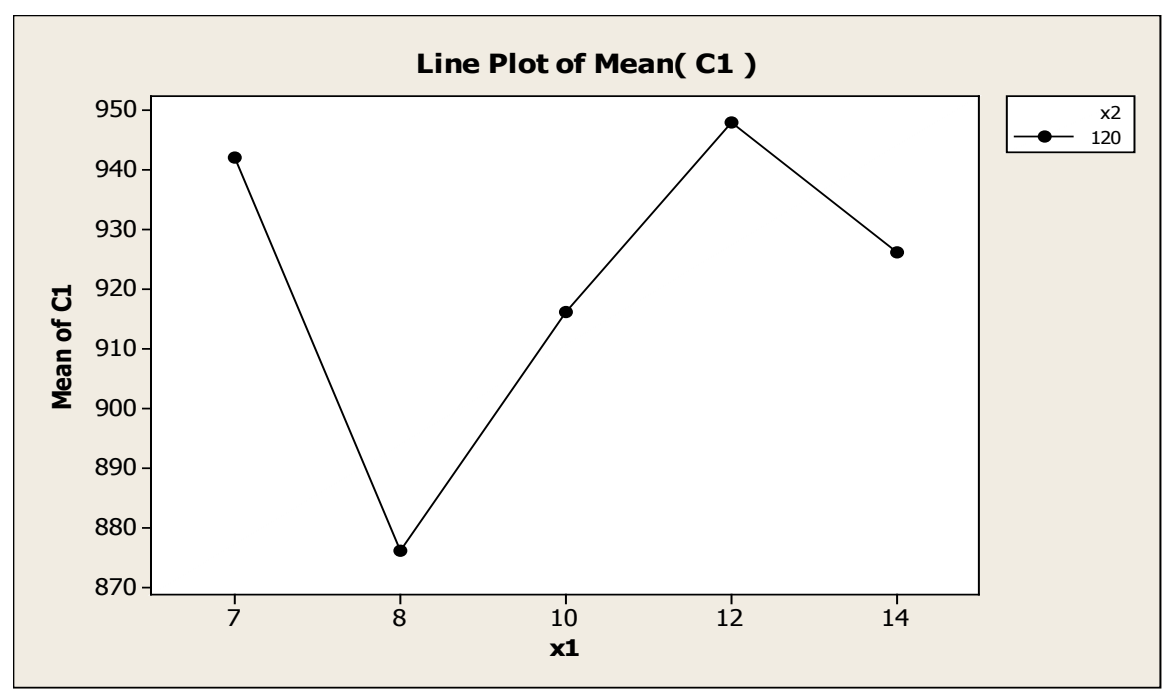

Where: The $\mathrm{X}$ axis is presents the changing in the gas flow. The $\mathrm{Y}$ axis is the mean of tensile strength.

Figure 9. A plot of tensile test result.

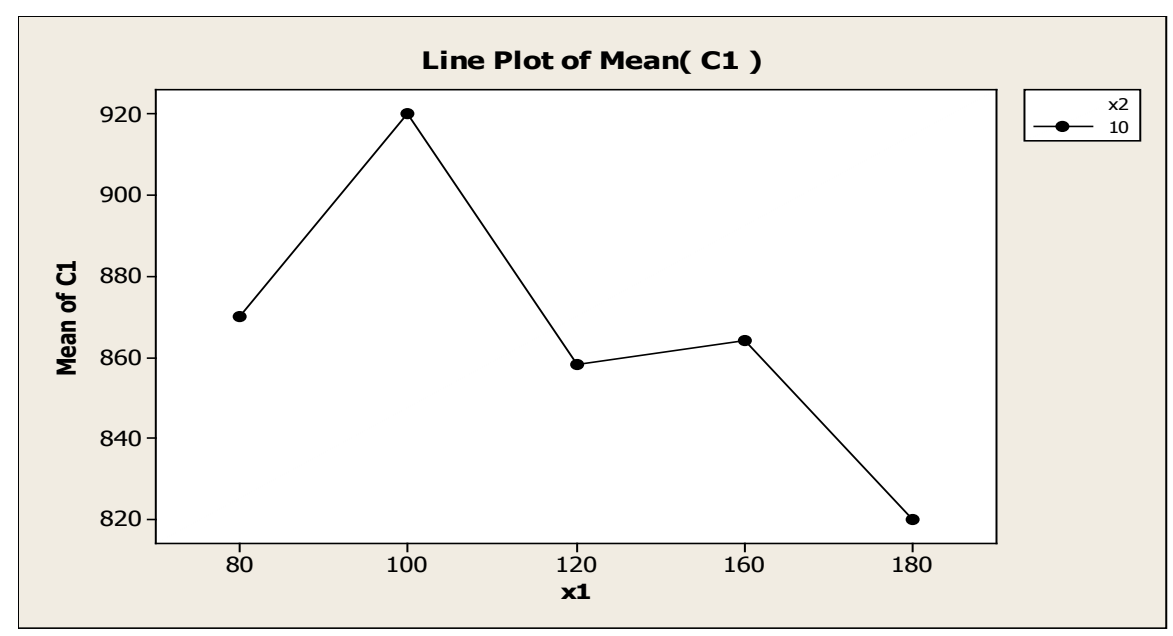

Where: The $\mathrm{X}$ axis is presents the changing in the gas flow. The $\mathrm{Y}$ axis is the mean of tensile strength.

Figure 10. A plot of tensile test result.

\subsection{Impact Test}

3.1.1. Analysis of Impact Energy Results for Fixed Gas Flow Rate and Variable Electrical Welding Current.

The welded samples were tested by charpy impact. An average of five impact specimens values were determined and tabulated in Table 4. These results are represented in a plot of impact energy with the variable welding current as shown in Figure 7.

Table 4 shows that the maximum value of absorbed energy achieved was $26.8 \mathrm{~J}$ at $120 \mathrm{~A}$ and the minimum value was $19 \mathrm{~J}$ at $80 \mathrm{~A}$. The range between the maximum and minimum absorbed energy was $7.8 \mathrm{~J}$. The results represented in Figure 7 shows that the effect of changing of welding current at a fixed gas flow rate, it is clear that increasing of welding current results to increasing in absorbed impact energy and toughness of the welded joint of 316 austenitic stainless steel.

\subsubsection{Analysis Result of the Fixed Welding Current and Changing of Gas Flow Rate}

The effect of gas flow rate on the impact energy of the welded joints of studied stainless steel was also investi- 
gated. Table 5 presents the results for the impact tests for the various shielding gas flow rates at a fixed welding current of 120 Amperes. The average of five values of impact strength specimens were plotted against the various gas flow rates as presented in Figure 8.

From Table 5 the maximum value was achieved for impact test was $27.2 \mathrm{~J}$ at $\mathbf{1 4} \mathrm{L} / \mathrm{min}$ and the minimum value was $24 \mathbf{J}$ at $7 \mathrm{~L} / \mathrm{min}$. The range between the maximum and minimum value was $3.2 \mathrm{~J}$. Figure 8 shows the effect of changing of gas flow rate at fixe welding current, and it is clear that increasing of gas flow rate caused increasing of absorbed energy which is reflecting increase in toughness of 316 stainless steel welded joints. The increasing of welding current and gas flow rate results an increasing of absorbed impact energy.

In Figure 7, an increasing welding current (as it is increased to $\mathbf{1 2 0} \mathrm{A}$ ) the absorbed impact energy is increased while at low current $(\mathbf{8 0}$ A) the impact energy was decreased. In Figure $\mathbf{8}$ where at increased gas flow rate (as it is increased up to $14 \mathrm{~L} / \mathrm{min}$ ) the absorbed impact energy is increased while at low gas flow rate (7 $\mathrm{L} / \mathrm{min}$ ) the impact energy was decreased.

\subsection{Tensile Test}

\subsubsection{Analysis of Fixed Gas Flow Rate and Changing of Welding Electrical Current}

Tensile testing was performed also for the study the effects of gas flow rates and welding currents on the tensile fracture load. For gas flow rate of $\mathbf{1 0} \mathrm{L} / \mathrm{min}$, welding currents of 80, 100, 120, 160, and $180 \mathrm{amps}$ were applied and five tensile samples were tested for each welding condition. Table 6 presents the received testing results. To demonstrate the tensile strength behavior, the results were plotted as shown in Figure 9.

Table 6 exhibits that the maximum tensile strength value was 920 MPa achieved at $100 \mathrm{~A}$ and the minimum value was $820 \mathrm{MPa}$ achieved at $\mathbf{1 8 0} \mathrm{A}$. The range between the maximum and minimum tensile strength is $\mathbf{1 0 0}$ MPa. Figure 9 represents the effect of changing of welding current on tensile strength. It is clear that increasing of electrical current caused decreasing tensile strength and hence the ductility of the welded joints.

\subsubsection{Analysis of the Fixed Electrical Current and Changing of Gas Flow Rate}

The effect of gas flow rate was also studied on the tensile strength behavior of stainless steel. Table 7 presents the results for tensile strength at a fixed welding current of $120 \mathrm{~A}$ but for various shielding gas flow rates. The average of five tensile testing samples was plotted against the shielding gas flow rate in Figure 10.

From the Table 7 the maximum tensile strength test value achieved was $948 \mathrm{MPa}$ at $12 \mathrm{~L} / \mathrm{min}$ and the minimum value was $876 \mathrm{MPa}$ at $8 \mathrm{~L} / \mathrm{min}$, the range between the maximum and minimum tensile strength value is 72 MPa.

Figure 10 shows the effect of changing of gas flow rate at fixe welding current and increasing of gas flow rate results an increase of tensile strength and hence the ductility of welded joints. Increasing of welding current, the tensile strength and ductility will be decreased while the increasing of gas flow rate caused increasing of tensile strength and ductility of welded joints.

In Figure 9 where for increased welding current as it is increased $(\mathbf{1 0 0} \mathrm{A})$ the tensile strength is increased while at low welding current $(\mathbf{8 0} \mathrm{A})$ the tensile strength was decreased. In Figure 10 whereas the gas flow is increased $(12 \mathrm{~L} / \mathrm{min})$, the absorbed tensile strength is increased while at low gas flow $(8 \mathrm{~L} / \mathrm{min})$ the tensile strength was decreased.

\subsection{Solidification and Microstructure Study}

\section{Solidification in the Fusion Zone}

A review of solidification cracking in austenitic stainless steel welds shows that the problem is more prevalent in fully austenitic and stabilized stainless steels. Solidification mode is a major determinant of cracking susceptibility; ensuring an FA or F mode ensures the best resistance to cracking. An important aspect of weld solidification is the effect of solidification kinetics on the phases formed. The eutectic reaction $\boldsymbol{L} \leftrightarrow \sigma+\gamma$ in stainless steels is not typical of the classical eutectic in the sense that the composition difference between $\sigma$ and $\gamma$ phases is minor. The relatively minor difference in thermodynamic stability of the two phases in the vicinity of the eutectic permits non-equilibrium solidification to a metastable phase obtained by extrapolation of the equilibrium phase boundaries [11]. Thus, the weld microstructure in stainless steels depends significantly on kinetic factors such as cooling rate and epitaxy, apart from equilibrium stability considerations. Under the rapid cooling and fast growth rates aided by epitaxy, the weld structure could solidify far away from equilibrium [12]. 
$\mathrm{As} \mathrm{Pb}$ is insoluble in molten steel, and austenite/ferrite has a low capacity for dissolving $\mathrm{S}$ and $\mathrm{P}$, all of these elements are vigorously segregated in the liquid during solidification. The resulting high impurity concentrations in the last liquid to solidify in the interdendritic regions have much lower melting points than those of the primary solidifying phase. The melting point of $\mathrm{Pb}$ is only $327^{\circ} \mathrm{C}-502^{\circ} \mathrm{C}$ and the melting point of the sulphides $(\mathrm{MnS}, \mathrm{FeS}, \mathrm{CrS})$ is about $1100^{\circ} \mathrm{C}-1200^{\circ} \mathrm{C}$, i.e. much lower than that of $\mathrm{Fe}\left(1538^{\circ} \mathrm{C}\right)$. If sufficiently high stresses are generated before final solidification, the boundaries with segregated $\mathrm{Pb}$ and sulfides may separate to form solidification cracks in the fusion zone, which providentially was not observed in this experimental study. Figure 11(a), Figure 11(b) shows the base metal (BM)/HAZ of AISI316.

\section{Microstructure in the HAZ}

Owing to the epitaxial nature of solidification, the grain boundary in the HAZ can link up with the solidification grain boundary in the fusion zone. Segregation of $\mathrm{S}, \mathrm{Pb}, \mathrm{Mn}$ and $\mathrm{P}$ during solidification means that these elements are able to diffuse into the HAZ from the fusion zone along the grain boundaries. The impurities and dissolved elements diffuse more rapidly along the grain boundaries than through the crystal lattice, which results in a local depression of the melting temperature. As a consequence, the grain boundary may melt during welding thermal cycles, but the local stress is insufficiently high to impose the melted grain boundary to separate in the HAZ. Figure 12 exhibits redistribution of elements in the melted zone and HAZ of a butt weld joining AISI316.

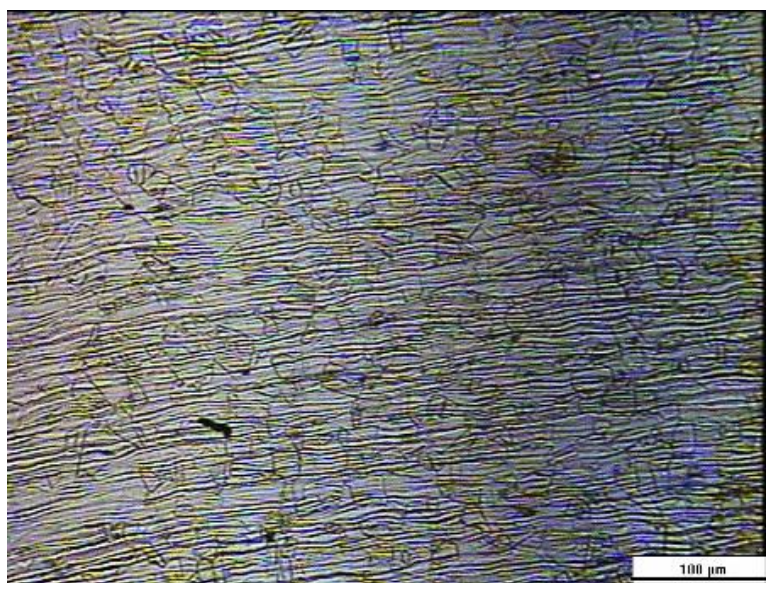

(a)

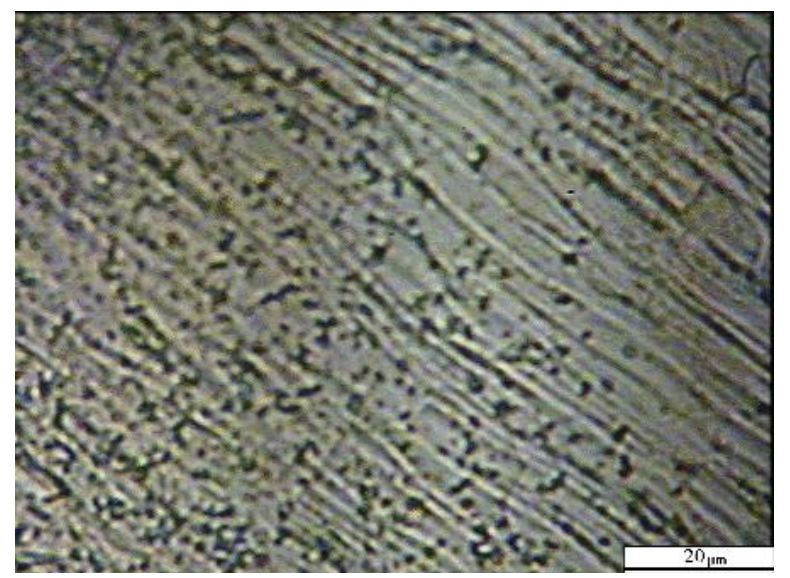

(b)

Figure 11. (a): SST 316 base metal. (b): SST 316 HAZ.

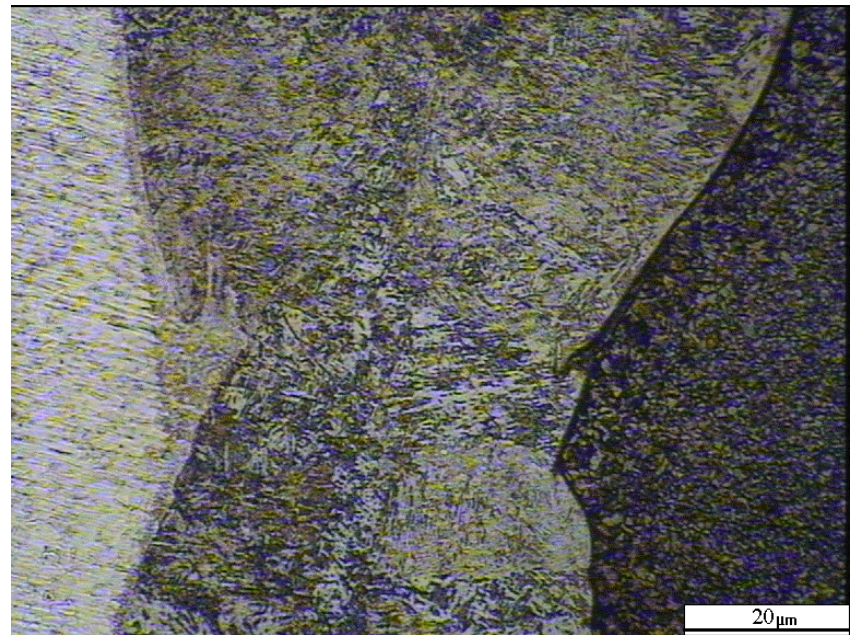

Figure 12. The redistribution of elements in the fusion zone of a butt weld joining AISI316. 
No cold cracking was observed during the study. The cooling rate which is estimated to be very high is responsible for the martensite structure formation. The martensitic structure in WZ and HAZ is the main reason for controlling the mechanical properties of the welded joints. The martensitic structure improves tensile strength but harms impact strength.

\section{Conclusions}

Referring to the previous discussion and the results obtained the following are concluded:

1) The welding parameters studied in this manuscript had high effect in the quality of welding and mechanical properties of the joints.

2) The electrical current welding parameter had a greatest effect in the weld quality. It is inversely proportional with tensile strength and directly proportional with impact strength.

3) The increasing electrical current resulted in the increasing impact energy and toughness but also caused decrease for tensile strength and ductility. But the increasing gas flow rate resulted in increasing impact and tensile strength which was an indication of improvement of toughness and ductility properties.

4) The gas flow rate had strong effective on weld quality of austenitic stainless steel 316 . It is directly proportional with impact and tensile strength.

\section{Acknowledgements}

Benghazi University, Faculty of Engineering (Industrial and Mechanical Departments) is gratefully acknowledged for the support of this research. Technical support from General Pipe Company is also gratefully acknowledged.

\section{References}

[1] Suresh Kumar, L., Verma, S.M., Radhakrishna Prasad, P., Kiran Kumar P. and Siva Shanker, T. (2011) Experimental Investigation for Welding Aspects of AISI 304 \& 316 by Taguchi Technique for the Process of TIG \& MIG Welding. International Journal of Engineering Trends and Technology, 2, 28-33.

[2] Murat, V. and Ahmet, A. (2004) On the Resistance Spot Weldability of Galvanized Interstitial Free Steel Sheets with Austenitic Stainless Steel Sheets. Journal of Materials Processing Technology, 153-154, 1-6. http://dx.doi.org/10.1016/j.jmatprotec.2004.04.063

[3] Emin, B., Dominique, K. and Marc, G. (2004) Application of Impact Tensile Testing to Spot Welded Sheets. Journal of Materials Processing Technology, 153-154, 80-86. http://dx.doi.org/10.1016/j.jmatprotec.2004.04.020

[4] Aslanlar, S. (2006) The Effect of Nucleus Size on Mechanical Properties in Electrical Resistance Spot Welding of Sheets Used in Automotive Industry. Materials and Design, 27, 125-131. http://dx.doi.org/10.1016/j.matdes.2004.09.025

[5] Anawa, E.M. and Olabi, A.G. (2006) Effects of Laser Welding Conditions on Toughness of Dissimilar Welded Components. Applied Mechanics and Materials, 5-6, 375-380. http://dx.doi.org/10.4028/www.scientific.net/AMM.5-6.375

[6] Bouyousfi, B., Sahraoui, T., Guessasma, S. and Tahar Chaouch, K. (2007) Effect of Process Parameters on the Physical Characteristics of Spot Weld Joints. Materials and Design, 28, 414-419. http://dx.doi.org/10.1016/j.matdes.2005.09.020

[7] Nizamettin, K. (2007) The Influence of Welding Parameters on the Joint Strength of Resistance Spot-Welded Titanium Sheets. Materials and Design, 28, 420-427.

[8] Shankar, V., Gill, T., Mannan, S. and Sundaresan, S. (2003) Solidification Cracking in Austenitic Stainless Steel Welds. Sadhana, 28, 359-382.

[9] Anawa, E.M. and Olabi, A.G., Anawa, E.M. and Olabi, A.G. (2008) Optimization of Tensile Strength of Ferritic/Austenitic Laser-Welded Components. Optics and Lasers in Engineering, 46, 571-577. http://dx.doi.org/10.1016/j.optlaseng.2008.04.014

[10] Hassan, E.M. (2008) Feasibility and Optimization of Dissimilar Laser Welding Components. Ph.D. Thesis, Dublin City University, Dublin.

[11] Kelly, T.F., Cohen, M. and Vandersande, J.B. (1984) Rapid Solidification of a Droplet-Processed Stainless Steel. Metallurgical Transactions A, 15, 819-833. http://dx.doi.org/10.1007/BF02644556

[12] Balluffi, R. (1982) Grain Boundary Diffusion Mechanism IN Metal's. Metallurgical Transactions A, 13A, $2069-2095$. http://dx.doi.org/10.1007/BF02648378 
Scientific Research Publishing (SCIRP) is one of the largest Open Access journal publishers. It is currently publishing more than 200 open access, online, peer-reviewed journals covering a wide range of academic disciplines. SCIRP serves the worldwide academic communities and contributes to the progress and application of science with its publication.

Other selected journals from SCIRP are listed as below. Submit your manuscript to us via either submit@scirp.org or Online Submission Portal.
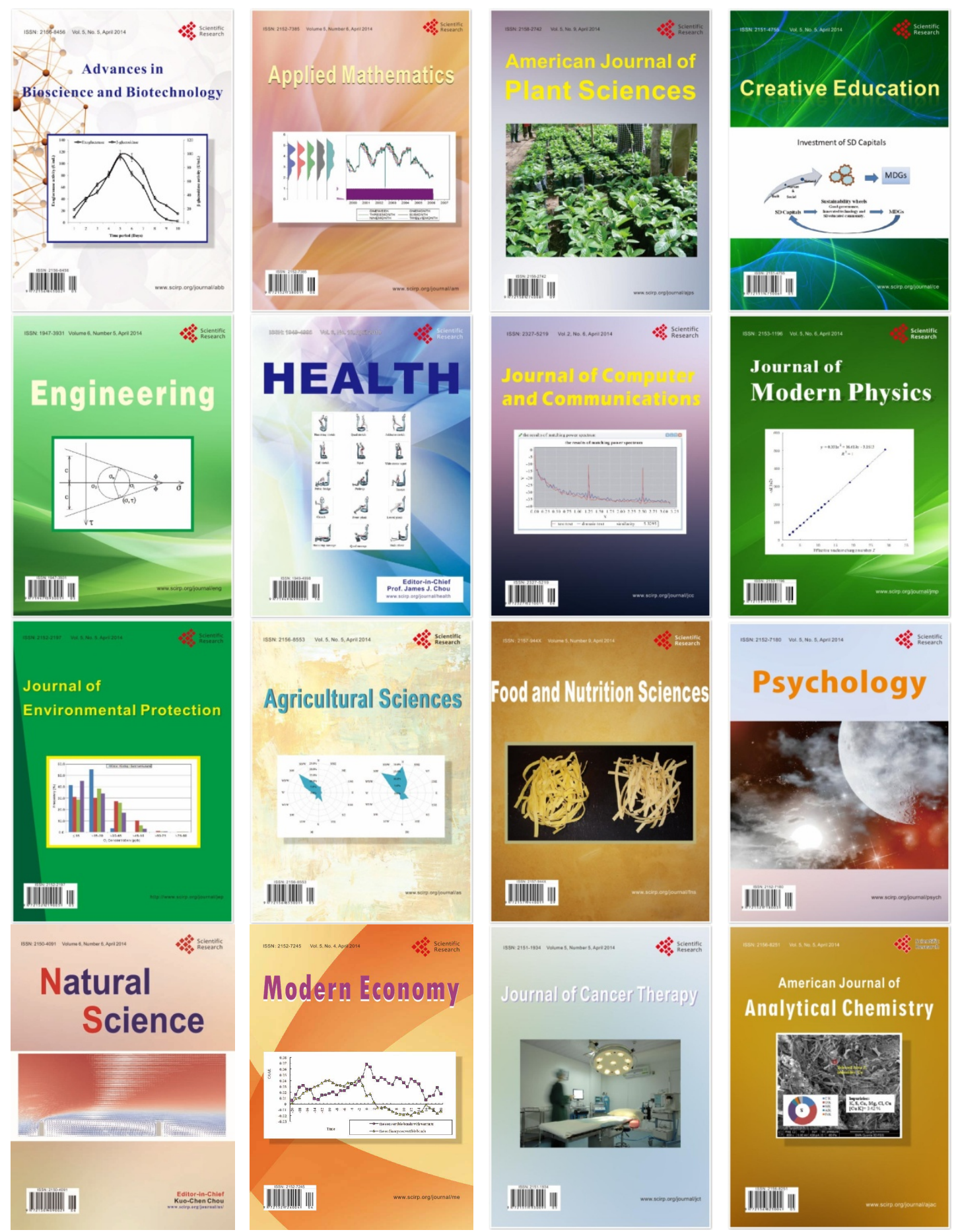